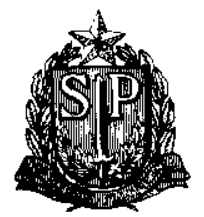

$B R$

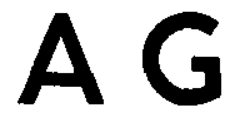

A
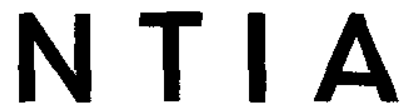

Revista Cientifica do Instituto Agronômico, Campinas

\title{
AVALIAÇÃO DA PRODUTIVIDADE DE LINHAGENS DE FEIJOEIRO RESISTENTES AO FUNGO DA ANTRACNOSE ${ }^{(1)}$
}

\author{
Antonio Sidney Pompeu, Seção de Genética, Instituto Agronômico
}

\section{RESUMO}

A capacidade produtiva de linhagens de feijoeiro (Phaseolus vulgaris) resistentes ao fungo da antracnose (Colletotrichum lindemuthianumi) pertencentes aos grupos Preto, Chumbinho e Diversos, foi estimada em experimentos em blocos ao acaso, instalados em Campinas, no cultivo das aguas de 1977, 1978 e 1979. Utilizaram-se os cultivares Moruna, Aroana e Carioca como controles para as linhagens dos grupos Preto, Chumbinho e Diversos respectivamente. Pela análise estatística dos dados obtidos pelas linhagens do grupo Preto, comuns aos ensaios de 1977 e 1978, 1978 e 1979, observou-se que as de prefixos 5-9-4-3-1-4, 5-9-4-3-1-5, 18-1-6 e 5-9-4-3-1-6, com médias de 2.100, 2.079, $2.055 \mathrm{e} 2.028 \mathrm{~kg} / \mathrm{ha}$, foram superiores ao 'Moruna', que produziu $1.580 \mathrm{~kg} / \mathrm{ha}$. No grupo Chumbinho, cujas linhagens foram avaliadas em 1978 e 1979, a de prefíxo 5-1-1-5-1-9, com $2.336 \mathrm{~kg} / \mathrm{ha}$, destacou-se das demais, embora esta produtividade média estivesse ao mesmo nível, estatisticamente, da verificada para o 'Aroana', $2.136 \mathrm{~kg} / \mathrm{ha}$. Para as linhagens do grupo Diversos, estudadas em 1978 e 1979, apenas 10-3-1 e 10-6-2, com produçöes médias de 3.133 e $2.823 \mathrm{~kg} / \mathrm{ha}$, foram superiores, respectivamente, a 2.375 e $2.355 \mathrm{~kg} / \mathrm{ha}$, observadas para o 'Carioca'. Outras linhagens deste grupo tiveram médias acima do controle, como 10-9-2, 10-9-1 e 10-5-1, com $2.698,2.686$ e $2.649 \mathrm{~kg} /$ ha (Carioca - $2.355 \mathrm{~kg} / \mathrm{ha}$ ) na ausência do patógeno. Nas análises conjuntas foram notados efeitos significativos para ano em onze dos doze grupos de experimentos e em apenas dois para a interação tratamento $x$ ano. As melhores linhagens serăo colocadas nos ensalos regionais e algumas terāo suas sementes aumentadas e colocadas à disposiçāo dos agricultores da regiāo de Campinas.

\section{INTRODUÇĀO}

No Brasil, em 1977 foram produzidas 2.290.007t de feijão, para uma área de $4.551 .032 \mathrm{ha}$, com rendimento médio de $503 \mathrm{~kg} / \mathrm{ha}$. Nos principais Estados produtores, isto é.
Paraná, Minas Gerais e São Paulo, os quais contribuem com $44,4 \%$ da produção brasileira, foram obtidas $576.885,283.360$ e $201.600 t$ de feijão, correspondendo a rendimentos de 712,473 e $576 \mathrm{~kg} /$ ha (1).

(1) Recebido para publicação a 11 de setembro de 1980. 
Dos fatores responsáveis pela baixa produtividade do feijoeiro em São Paulo, bem como nos demais Estados, as moléstias destacam-se como o mais importante. Destas, a antracnose, causada pelo fungo Colletotrichum lindemuthianum, é de grande importância por sua ocorrência nas diversas épocas de cultivo, pela redução que ocasiona na produção e pelo fato de o agente ter nas sementes o principal meio de disseminação.

Das medidas recomendadas para - controle desse patógeno, como rotação da cultura, uso de sementes sadias, pulverizações com fungicidas e utilização de cultivares resistentes (4), a última é considerada como a mais eficiente e mais econômica.

No programa de melhoramento em andamento na Seção de Genética, várias linhagens homozigotas para $o$ gene Are, que confere resistência aos grupos de antracnose que ocorrem no Brasil, já foram obtidas $(2,3)$, sendo objetivo deste trabalho mostrar as produções conseguidas por aquelas pertencentes aos grupos de feijão Preto, Chumbinho e Diversos.

\section{MATERIAL E METODO}

Linhagens resistentes ao fungo da antracnose e enquadradas nos grupos Chumbinho, Preto e Diversos tiveram suas produções avaliadas nos ensaios instalados nas águas de 1978 e 1979, no Centro Experimental de Campinas. Algumas linhagens do grupo Preto foram avaliadas, para a mesma época de cultivo e local, nos anos de 1977 e 1978. Todas as linhagens estudadas são portadoras do gene Are, sendo que a obtenção da maioria delas já foi descrita (2), enquanto outras do grupo Diversos são origi- nárias de cruzamentos múltiplos envolvendo 'Carioca' e Cornell 49-242. Nesses experimentos, em blocos ao acaso com duas ou três repetições, cada parcela foi constituída por uma linha de $5 \mathrm{~m}$, espaçada de $0,50 \mathrm{~m}$, sendo de $0,20 \mathrm{~m}$ a distância entre covas. O número de sementes usado foi quatro por cova, para no desbaste deixar duas plantas por cova ou 50 por linha. Foram utilizados como controles os cultivares Aroana e Moruna, resistentes apenas ao grupo Brasileiro I de antracnose, e Carioca, suscetível ao agente dessa moléstia (2), nos ensaios constituídos por linhagens dos grupos Chumbinho, Preto e Diversos respectivamente.

A adubação usada nos experimentos era constituída de $100 \mathrm{~kg}$ de $\mathrm{P}_{2} \mathrm{O}_{5} /$ ha (superfosfato simples) no plantio e de $40 \mathrm{~kg}$ de $\mathrm{N} / \mathrm{ha}$ (sulfato de amônio) em cobertura, após o desbaste.

Três a quatro pulverizaçōes de uma mistura de Endrin $\left(2 \mathrm{~cm}^{3} /\right.$ litro), Benlate $(0,7 \mathrm{~g} /$ litro $)$ e Folidol $\left(1 \mathrm{~cm}^{3} /\right.$ litro), foram aplicadas após o desbaste e continuadas em intervalos de quinze e vinte dias, para o controle de pragas e agentes patogênicos.

Como no período 1977-1979 foram avaliadas as produções de 114 linhagens do grupo Preto e em 1978 e 1979, de 57 do Chumbinho e de 171 do grupo Diversos, a análise estatística foi efetuada somente para as linhagens comuns aos ensaios de 1977 e 1978 e 1978 e 1979, após a verificação da homogeneidade dos quadrados médios residuais.

O teste de Dunnett a $5 \%$ foi utilizado na comparação das médias das linhagens com as dos respectivos controles. 
3. RESULTADOS E DISCUSSÃO

As produções obtidas pelas linhagens do grupo Preto, e pelo 'Moruna', no plantio das águas em 1977 e 1978, estão contidas no quadro 1 .
Observa-se que, para o conjunto em que o Moruna produziu em média $2.173 \mathrm{~kg} /$ ha $(1.427,2.920)$, apenas a linhagem 3-3-11, proveniente do primeiro retrocruzamento para Moruna, com $2.513 \mathrm{~kg} / \mathrm{ha}(1.960,3.067)$,

QUADRO 1 - Produçōes obtidas pelas linhagens resistentes a c. lindemuthianum, do grupo Preto, e pelo cultivar Moruna, no plantio das águas de 1977 e 1978

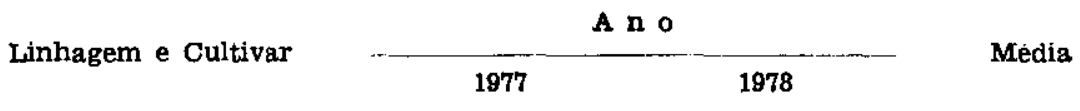

$\mathrm{kg} / \mathrm{ha} \quad \mathrm{kg} / \mathrm{ha} \quad \mathrm{kg} / \mathrm{ha}$

$\mathrm{BC}_{1}$ C49-242. Moruna

$\begin{array}{llll}3-3-11 & 1.960 & 3.067 & 2.513 \\ 24-11-1 & 1.200 & 2.693 & 1.946 \\ 3-3-1 & 1.227 & 2.280 & 1.753\end{array}$

$\mathrm{BC}_{8}$ C49-242 . Moruna

$\begin{array}{llll}5-9-4-8 & 1.720 & 2.533 & 2.126 \\ 5-9-4-5 & 1.333 & 2.667 & 2.000 \\ 5-9-4-7 & 1.240 & 2.640 & 1.940 \\ 5-9-4-11 & 1.267 & 2.600 & 1.933 \\ 5-9-4-1 & 1.240 & 2.427 & 1.833 \\ 5-9-4-2 & 1.253 & 2.213 & 1.733\end{array}$

Moruna

1.427

2.920

2.173

Dunnett a $\mathbf{5 \%}$ 368

$\mathrm{BC}_{2}$ C49-242 . Moruna

$\begin{array}{llll}5-9-4-16 & 1.500 & 2.800 & 2.150 \\ 5-9-4-17 & 1.500 & 2.693 & 2.096 \\ 5-9-4-15 & 1.333 & 2.813 & 2.073\end{array}$

$\mathrm{BC}_{1}$ C49-242 . Moruna

3-3-10

1.367

2.440

1.903

Moruna

1.333

2.930

2.131

Dunnett a $\mathbf{5 \%}$

$\mathbf{B C}_{\mathbf{x}}=1.0^{\circ}$ retrocruzamento, $\mathbf{B C _ { 2 }}=2 .^{\circ}$ retrocruzamento. 
destacou-se das demais, embora não diferindo estatisticamente do controle. A análise estatística conjunta mostrou que os efeitos de tratamento e de ano foram significativos, o mesmo não ocorrendo para a interação tratamento $\mathrm{x}$ ano.

Produções médias de 2.150 $(1.500,2.800), 2.096 \quad(1.500$, $2.693) \mathrm{e} 2.073 \mathrm{~kg} / \mathrm{ha}(1.333,2.813)$ foram conseguidas pelas linhagens 5-9-4-16, 5-9-4-17 e 5-9-4-15, respectivamente, enquanto Moruna obteve $2.131 \mathrm{~kg} / \mathrm{ha}(1.333,2.930)$. Efeitos significativos foram notados para tratamento, ano e interação tratamento $\mathrm{x}$ ano.

$O$ efeito significativo de ano para cada um dos grupos analisados deve-se à estiagem observada em 1977, a qual refletiu bastante nas produções, tornando-as bastante inferiores às verificadas em 1978.

Das linhagens do grupo Preto avaliadas em 1978 e 1979, as identificadas como 5-9-4-3-1-4, 5-9-4-3-1-5, 18-1-6 e 5-9-4-3-1-6, com produções médias de $2.100(2.400,1.800)$ $2.079 \quad(2.340, \quad 1.818), \quad 2.055$ $(2.220,1.891)$ e $2.028 \mathrm{~kg} / \mathrm{ha}$ $(2.420,1.636)$, foram superiores ao Moruna, que produziu $1.580 \mathrm{~kg} / \mathrm{ha}$ (1.560, 1.600) (Quadro 2).

Efeitos significativos foram notados pela análise conjunta das produções obtidas, para tratamento e ano, o que não aconteceu para a interação tratamento $\mathrm{x}$ ano. Isso mostra que houve diferenças, entre algumas linhagens, em relação à capacidade produtiva, quanto a ano, e que, de modo geral, elas tiveram um comportamento idêntico nos anos estudados.

As produções alcançadas pelas linhagens do grupo Chumbinho e por
Aroana, em 1978 e 1979, são apresentadas nos quadros 3 e 4 .

Nota-se que apenas a produção média da linhagem 5-1-1-6-1-29 de $1.983 \mathrm{~kg} / \mathrm{ha}(2.560,1.406)$, esteve bem próxima da conseguida pelo Aroana, $2.027 \mathrm{~kg} / \mathrm{ha}(2.600,1.455)$. No outro conjunto, em que o Aroana produziu $2.194 \mathrm{~kg} / \mathrm{ha}(2.933,1.455)$, as maiores produções médias foram obtidas pelas linhagens 5-1-1-6-1-6, 5-1-1-5-1-5 e 5-1-1-5-1-7 com 2.214 $(2.987, \quad 1.442), \quad 2.180 \quad(3.027$, $1.333)$ e $2.052 \mathrm{~kg} / \mathrm{ha}(2.880,1.224)$.

Os resultados obtidos com a análise estatística para cada um dos conjuntos de linhagens mostrou que o efeito de ano foi significativo, o que não aconteceu para tratamento e para $\mathrm{a}$ interação tratamento $\mathrm{x}$ ano.

Das linhagens apresentadas no quadro 4 , as produçōes médias mais elevadas foram verificadas para as de prefixos 5-1-1-5-1-9, 5-1-1-6-1-15 e 5-1-1-6-1-14, com 2.336 (2.940, $1.733), 2.228(2.880,1.576) \quad \mathrm{e}$ $2.222 \mathrm{~kg} / \mathrm{ha}(2.700,1.745)$, comparadas com a conseguida pelo Aroana: $2.136 \mathrm{~kg} / \mathrm{ha}(2.600,1.673)$.

Embora a análise conjunta das produções de 1978 e 1979 tenha mostrado efeito de tratamento, nenhuma linhagem foi superior ao controle. A interação tratamento $x$ ano não foi significativa, mas o efeito de ano foi, sendo as produçôes de 1978 superiores às observadas em 1979.

As diferenças em produções verificadas entre 1978 e 1979 , para as linhagens do grupo Chumbinho, devem-se, provavelmente, a um nível inferior de fertilidade do solo onde os experimentos foram instalados, a uma incidência maior das bacterioses 
QUADRO 2 - Produçóes conseguidas pelas linhagens resistentes ao fungo da antracnose, pertencentes ao grupo Preto, e por 'Moruna', no plantio das éguas de 1978 e 1979, no Centro Experimental de Campinas

Linhagem e Cultivar

BC. Cornell 49-242 . Moruna

$$
\begin{aligned}
& 5-9-4-3-1-4 \\
& 5-9-4-3-1-5
\end{aligned}
$$

Moruna x Cornell 49-242

18-1-6

2.220

2.420

2.380

2.020

2.080

1.980

1.840

2.040

1.860

2. 160

1.820

1.640

H5075-12-1

$\mathrm{BC}_{2}$ Cornell 49-242 . Moruna

$$
\begin{aligned}
& 5-9-4-3-1-7 \\
& 5-9-4-3-1-12
\end{aligned}
$$

H4775-22-1

H4875-26-1

F14975-24-1

Moruna

Dunnett a $5 \%$

$\mathrm{BC}_{3}$ Cornell 49-242 . Moruna

$$
\text { 5-9-4-3-1-1 }
$$

1.780

1.640

1.480

1.600

1.440

1.560
A n o

Média $\mathrm{kg} / \mathrm{ha}$

2.100

2.079

2.055
2.028

1.990

1.964

1.912

1.899

1.818

1.856

1.873

1.473

1.756

1.636

1.748

1.734

1.309

1.710

1.600

1.683

1.727

1.473

1.626

1.327

1.483

1.636

1.558

1.236

1.418

1.382

1,411

1.600

1.580 419

$\mathrm{BC}_{2}=2 .^{\circ}$ retrocruzamento. 
QUADRO 3 - Produtividade de linhagens de feijoeiro do grupo Chumbinho, resistentes ao microrganismo da antracnose, e do controle 'Aroana', nos experimentos instalados nas águas de 1978 e 1979, em Campinas

Linhagem e Cultivar

A n o

\section{8}

1979

Média

$\mathrm{kg} / \mathrm{ha}$

kg/ha

$\mathrm{kg} / \mathrm{ha}$

$\mathrm{BC}_{2}$ Cornell 49-242 . Aroana

$\begin{array}{rrrr}5-1-1-6-1-29 & 2.560 & 1.406 & 1.983 \\ 5-1-1-6-1-32 & 2.660 & 1.091 & 1.875 \\ 5-1-1-6-1-25 & 2.280 & 1.285 & 1.782 \\ 5-1-1-6-1-31 & 2.200 & 1.248 & 1.724 \\ 5-1-1-6-1-22 & 2.160 & 1.200 & 1.680 \\ 5-1-1-6-1-24 & 1.980 & 1.152 & 1.566 \\ 5-1-1-6-1-23 & 2.040 & 1.091 & 1.565 \\ 5-1-1-6-1-30 & 1.940 & 1.176 & 1.558 \\ 5-1-1-6-1-26 & 2.100 & 885 & 1.492 \\ 5 & & & 2.027 \\ 5 & & 1.455 & 321\end{array}$

$\mathrm{BC}_{2}$ Cornell 49-242 . Aroana

$\begin{array}{rrrr}5-1-1-6-1-6 & 2.987 & 1.442 & 2.214 \\ 5-1-1-5-1-5 & 3.027 & 1.333 & 2.180 \\ 5-1-1-5-1-7 & 2.880 & 1.224 & 2.052 \\ 5-1-1-5-1-8 & 2.627 & 1.236 & 1.931 \\ 5-1-1-5-1-3 & 2.720 & 1.079 & 1.899 \\ 5-1-1-5-1-4 & 2.587 & 1.176 & 1.881 \\ 5-1-1-6-1-2 & 2.653 & 1.067 & 1.860 \\ 5-1-1-5-1-1 & 2.587 & 1.079 & 1.833 \\ 5-1-1-6-1-3 & 2.253 & 1.139 & 1.696 \\ 5-1-1-6-1-1 & 2.187 & 921 & 1.554 \\ & & & 2.194 \\ \text { na } & 2.933 & 1.455 & 414\end{array}$

Dunnett a $5 \%$

414 
e de fungos do solo, os quais alteram o número final de plantas por parcela.
As produções e médias das linhagens do grupo Diversos e do 'Ca-

QUADRO 4 - Produçōes de sementes de linhagens de feijoeiro do grupo Chumbinho, resistentes ao agente da antracnose, e do controle 'Aroana', nos ensaios das águas de 1978 e 1979, em Campinas

Linhagem e Cultivar

A n o

$1978 \quad 1979 \quad$ Média

$\mathrm{kg} / \mathrm{ha}$

kg/ha

$\mathbf{k g} / \mathbf{h a}$

$\mathrm{BC}_{\text {。 }}$ Cornell 49-242 . Aroana

$5-1-1-5-1-9$
$5-1-1-6-1-15$
$5-1-1-6-1-14$
$5-1-1-6-1-20$
$5-1-1-5-1-15$
$5-1-1-5-1-10$
$5-1-1-6-1-19$
$5-1-1-5-1-6$
$5-1-1-6-1-17$
$5-1-1-6-1-18$
$5-1-1-6-1-27$
$5-1-1-6-1-8$
$5-1-1-6-1-21$
$5-1-1-6-1-13$
$5-1-1-6-1-4$
$5-1-1-6-1-5$
$5-1-1-6-1-16$
$5-1-1-6-1-28$
$5-1-1-6-1-13$

2.940

1.733

2.336

2.880

1.576

2.228

2.700

1.745

2.222

2.600

1.784

2.197

2.640

1.745

2.192

2.740

1.636

2.188

2.720

1.612

2.166

2.700

1.588

2.144

2.660

1.479

2.069

2. 720

1.418

2.069

2.600

1.527

2.063

2.600

1.527

2.063

2.380

1.745

2.062

2.400

1.636

2.018

2. 500

1.467

1.983

2.200

1.515

1.857

2.120

1.503

1.811

2. 220

1.358

1.789

2.040

1.515

1.777

2.136

Aroane.

2.600

1.673

Dunnett a $5 \%$ 
Vol. 41, Art. n. ${ }^{\circ} 7$

rioca' encontram-se nos quadros 5 , 6 e 7.

Das linhagens constantes do quadro 5, para os ensaios nos quais a produção média do Carioca foi $2.375 \mathrm{~kg} / \mathrm{ha}(2.580$ e 2.170$) \mathrm{em}$ 1978 e 1979, apenas a linhagem 10-3-1, com tegumento rosado e com listras marrons, foi superior, estatisticamente, ao controle: $3.133 \mathrm{~kg} / \mathrm{ha}$ $(3.540,2.727)$. A linhagem $17-5-2$, com sementes de coloração idêntica à do Carioca, isto é, creme com listras marrons, destacou-se das demais, com uma produtividade média de $2.491 \mathrm{~kg} / \mathrm{ha}(2.800,2.182)$.

Os resultados mostraram, pela análise da variância, que existem diferenças quanto à produtividade entre alguns dos tratamentos e que os efeitos de ano e da interação tratamento $x$ ano não foram significativos.

No outro grupo (quadro 5), em que o Carioca produziu em média $2.355 \mathrm{~kg} /$ ha $(2.540,2.170)$, a linhagem 10-6-2, com $2.823 \mathrm{~kg} /$ ha $(2.980$, 2.667), superou estatisticamente o controle. As linhagens 10-9-2, 10-9-1 e 10-5-1, embora não diferindo estatisticamente do 'Carioca', destacaram-se das demais, com 2.698 $(2.960,2.436), 2.686 \quad(2.960$, $2.412)$ e $2.649 \mathrm{~kg} / \mathrm{ha}(2.960,2.339)$. Essas linhagens possuem sementes com coloração de tegumento igual à do Carioca, com exceção da 10-9-2, cuja cor é rosada, com listras pretas.

Efeitos significativos foram observados para tratamento e ano, o que não aconteceu para a interação tratamento $x$ ano. $O$ efeito de ano pode ser explicado principalmente pela alta incidência de ferrugem no plantio das águas de 1979 , o que não aconteceu em 1978, para a mesma época de cultivo.

Nota-se, no quadro 6 , que as linhagens 7-1-21, com sementes de cor igual à do 'Carioca', e 10-1-22, com tegumento de cor rosada com listras marrons, produziram, em média, 2.103 $(2.340,1.867) \quad \mathrm{e}$ $2.038 \mathrm{~kg} / \mathrm{ha}(1.980,2.097)$. A produtividade média do 'Carioca' foi $2.155 \mathrm{~kg} / \mathrm{ha}(2.080,2.230)$.

Para essas linhagens, pela análise dos dados de 1978 e 1979, verificou-se que tratamento e ano foram significativos, o que não ocorreu com a interação tratamento $\mathrm{x}$ ano. Isso demonstra que existem, pelo menos, algumas linhagens que diferem quanto à produtividade, que em 1979 as condições foram mais desfavoráveis ao desenvolvimento das plantas devido, principalmente, à alta incidência da ferrugem e, também, que as linhagens tiveram praticamente o mesmo comportamento nos dois anos em estudo.

No outro conjunto, em que o Carioca produziu em média $2.325 \mathrm{~kg} /$ /ha $(2.420,2.230)$, as linhagens 10-1-11 e 10-1-9, de sementes de coloração rosada com listras marrons, destacaram-se das demais, com 2.600 $(3.080,2.121)$ e $2.531 \mathrm{~kg} / \mathrm{ha}$ $(2.880,2.182)$, sem serem superiores, estatisticamente, ao controle. Para este grupo de linhagens, os efeitos de tratamento, ano e tratamento $\mathrm{x}$ ano foram significativos.

Observa-se, no quadro 7 , que as linhagens H7627-18-4 e H7627-18-1, com tegumento de cor rosada com listras inarrons, sobressaíram-se das demais, produzindo em média 2.579 $(2.340,2.818)$ e $2.239 \mathrm{~kg} / \mathrm{ha}$ $(2.660,1.818)$, tendo o Carioca produzido $2.197 \mathrm{~kg} / \mathrm{ha}(2.740,1.654)$. 
QUADRO 5 - Produçōes de sementes de linhagens do grupo Diversos, resistentes ao patógeno da antracnose, e do controle 'Carioca' nos ensaios instalados nas águas de 1978 e 1979, no Centro Experimental de Campinas

\begin{tabular}{cccc}
\hline & & \\
Linhagem e Cultivar & 1978 & Média \\
\cline { 2 - 4 } & $\mathrm{kg} / \mathrm{ha}$ & $\mathrm{kg} / \mathrm{ha}$ & $\mathrm{kg} / \mathrm{ha}$ \\
\hline $10-3-1$ & & & \\
$17-5-2$ & 3.540 & 2.727 & 3.133 \\
$16-4-1$ & 2.800 & 2.182 & 2.491 \\
$1-9-7$ & 2.240 & 1.794 & 2.017 \\
$1-9-3$ & 2.040 & 1.964 & 2.002 \\
$1-9-5$ & 1.560 & 2.267 & 1.913 \\
$1-9-2$ & 1.760 & 1.867 & 1.813 \\
$1-9-4$ & 1.720 & 1.855 & 1.787 \\
$1-9-6$ & 1.620 & 1.855 & 1.737 \\
$1-9-8$ & 1.780 & 1.673 & 1.726 \\
Carioca & 1.640 & 1.539 & 1.589 \\
Dunnett a $5 \%$ & & & 2.375 \\
\hline
\end{tabular}

Carioca $\times$ Cornell 49-242

$\begin{array}{llll}10-6-2 & 2.980 & 2.667 & 2.823 \\ 10-9-2 & 2.960 & 2.436 & 2.698 \\ 10-9-1 & 2.960 & 2.412 & 2.686 \\ 10-5-1 & 2.960 & 2.339 & 2.649 \\ 8-5-3 & 2.240 & 2.012 & 2.126 \\ 8-5-2 & 2.220 & 1.721 & 1.970\end{array}$

HRA - 1

2.780

4.188

1.984

Carioca

2.540

2.170

2.355 
QUADRO 6 - Produtividade de linhagens de feijoeiro resistentes ao fungo da antracnose, pertencentes ao grupo Diversos, e do controle 'Caríoca', observada no plantio das águas de 1978 e 1979, no Centro Experimental de Campinas

\begin{tabular}{|c|c|c|c|}
\hline \multirow{2}{*}{ Linhagem e Cultivar } & \multicolumn{2}{|c|}{ A $n$ o } & \multirow{2}{*}{ Média } \\
\hline & 1978 & 1979 & \\
\hline \multicolumn{4}{|l|}{$\mathrm{BC}_{1} \mathbf{C 4 9 - 2 4 2}$. Carioca } \\
\hline $7-1-21$ & 2.340 & 1.867 & 2.103 \\
\hline \multicolumn{4}{|l|}{ Carioca $\times$ Cornell $49-242$} \\
\hline $10-1-22$ & 1.980 & 2.097 & 2.038 \\
\hline $12-2-2$ & 2.260 & 1.721 & 1.990 \\
\hline H7627-14-2 & 2.260 & 1.491 & 1.875 \\
\hline H7623-15-1 & 2.380 & 1.261 & 1.820 \\
\hline H7627-14-1 & 2.060 & 1.552 & 1.806 \\
\hline H7623-16 & 2.540 & 945 & 1.742 \\
\hline H7627-14-4 & 2.140 & 1.333 & 1.736 \\
\hline H7623-1-3 & 2.140 & 1.055 & 1.597 \\
\hline H7623-7-1 & 2.000 & 1.139 & 1.569 \\
\hline H7627-13-2 & 1.920 & 1.176 & 1.548 \\
\hline H7623-1-1 & 1.960 & 994 & 1.477 \\
\hline Carloca & 2.080 & 2.230 & 2.155 \\
\hline Dunnett a $5 \%$ & & & 415 \\
\hline
\end{tabular}

Carioca $x$ Cornell $49-242$

$\begin{array}{lrrr}10-1-11 & 3.080 & 2.121 & 2.600 \\ 10-1-9 & 2.880 & 2.182 & 2.531 \\ 10-1-20 & 2.300 & 2.218 & 2.259 \\ 8-1-9 & 2.020 & 1.733 & 1.876 \\ 2-1-17 & 2.300 & 1.042 & 1.671 \\ 6-3-1 & 2.120 & 1.212 & 1.666 \\ 2-1-22 & 2.040 & 878 & 1.459 \\ \text { oca } & 2.420 & 2.230 & 2.325 \\ \text { nett a } 5 \% & & & 352\end{array}$

$\mathrm{BC}_{1}=10^{\circ}$ retrocruzamento. 
QUADRO 7 - Produçöes conseguidas pelas linhagens do grupo Diversos, resistentes ao agente da antracnose, e por 'Carioca' nos ensajos da época das águas de 1978 e 1979, em Campinas

\begin{tabular}{|c|c|c|c|}
\hline \multirow{2}{*}{ Linhagem e Cultivar } & \multicolumn{2}{|c|}{ A n o } & \multirow{2}{*}{ Média } \\
\hline & 1978 & 1979 & \\
\hline & $\mathbf{k g} / \mathbf{h a}$ & $\mathrm{kg} / \mathrm{ha}$ & $\mathbf{k g} / \mathbf{h a}$ \\
\hline H7627-18-4 & 2.340 & 2.818 & 2.579 \\
\hline H7627-18-1 & 2.660 & 1.818 & 2.239 \\
\hline H7627-17-4 & 2.320 & 1.636 & 1.978 \\
\hline H7627-18-5 & 2.240 & 1.673 & 1.956 \\
\hline H7627-16-2 & 2.220 & 1.673 & 1.946 \\
\hline H7627-15-4 & 2.240 & 1.618 & 1.929 \\
\hline H7627-18-2 & 2.300 & 1.545 & 1.922 \\
\hline H7627-17-2 & 2.180 & 1.582 & 1.881 \\
\hline H7627-18-3 & 2.120 & 1.636 & 1.878 \\
\hline H7627-19.3 & 2.240 & 1.454 & 1.847 \\
\hline H7627-18-6 & 2.640 & 1.018 & 1.829 \\
\hline H7627-18-7 & 2.300 & 1.200 & 1.750 \\
\hline H7627-19-4 & 2.120 & 1.345 & 1.732 \\
\hline H7627-19-2 & 2.220 & 964 & 1.592 \\
\hline \multicolumn{4}{|l|}{ Carioca } \\
\hline \multirow[t]{2}{*}{ Dunnett a $\mathbf{5} \%$} & 2.740 & 1.654 & 2.197 \\
\hline & & & 499 \\
\hline \multicolumn{4}{|l|}{ Carioca $\times$ Cornell 49-242 } \\
\hline $10-1-3$ & 2.640 & 2.036 & 2.338 \\
\hline $17-4-2$ & 2.260 & 2.400 & 2.330 \\
\hline $2-6-1$ & 2.280 & 1.618 & 1.949 \\
\hline $10-1-2$ & 2.720 & 927 & 1.823 \\
\hline H7633-3-3 & 2.100 & 1.400 & 1.750 \\
\hline Carioca & 2.460 & 1.654 & 2.057 \\
\hline Dunnett a $5 \%$ & & & 451 \\
\hline
\end{tabular}


Vol. 41, Art. n. ${ }^{\circ} 7$

As maiores produções médias, para as linhagens em que a produção do Carioca (parte inferior do quadro 7) foi $2.057 \mathrm{~kg} / \mathrm{ha}(2.460 \mathrm{e}$ 1.654) em 1978 e 1979 respectivamente, foram conseguidas por 10-1-3, de sementes dc cor rosada com listras marrons, e 17-4-2, com tegumento rosado com listras pretas: 2.338 $(2.640,2.036)$ e $2.330 \mathrm{~kg} / \mathrm{ha}$ (2.260, 2.400).

A análise estatística conjunta para cada um dos grupos de linhagens do quadro 7 mostrou que apenas o efeito de ano foi significativo.

Pelos resultados obtidos, observase que, das linhagens do grupo Preto, apenas as de prefixos 5-9-4-3-1-4 e 5-9-4-3-1-5, estudadas em 1978 e 1979 , foram superiores em produtividade ao 'Moruna'. Essas linhagens, que resultaram do segundo retrocruzamento para 'Moruna' e que, morfologicamente, são semelhantes a este cultivar, são portadoras de outros genes de Cornell 49-242, além do Are, possibilitando, com isso, uma melhoria no nível de produtividade do pai recorrente nas condições estudadas.

No grupo Diversos apenas a linhagem 10-3-1, com coloração de tegumento diferente, ultrapassou esta- tisticamente o Carioca em produção. Essa linhagem e outras com produções maiores que a do Carioca, embora não diferindo dele do ponto de vista estatístico, possuem também resistência à(s) raça(s) do fungo da ferrugem que ocorre(m) em Campinas, mostrando que são portadoras de outros genes de Cornell 49-242, em adição ao Are. O Carioca comporta-se como suscetível ao patógeno causador da ferrugem.

Para o grupo Chumbinho, algumas das linhagens obtidas resultantes do segundo retrocruzamento para o 'Aroana', são, nos aspectos morfológicos e de produtividade, semelhantes a este cultivar.

Das linhagens estudadas, as melhores dentro de cada grupo farão parte de ensaios a serem instalados nas principais regiōes produtoras paulistas, enquanto algumas terão suas sementes aumentadas e colocadas à disposição, principalmente, dos agricultores da região de Campinas. Como as produções obtidas por essas linhagens foram na ausência do fungo da antracnose, elas constituem material valioso para aumento e estabilização do rendimento, notadamente nas áreas onde esta moléstia ocorre com freqüência, afetando o desenvolvimento e a produção do feijoeiro.

\section{PRODUCTIVITY OF DRY BEAN LINES (PHASEOLUS VULGARIS) RESISTANT TO THE ANTHRACNOSE FUNGUS (COLLETOTRICHUM LINDEMUTHIANUM)}

\section{SUMMARY}

With the objective of knowing the yielding ability of dry bean lines of Preto, Diversos and Chumbinho groups resistant to the anthracnose agent, trials in randomized complete-block design were carried out in the Main Experimental Station of Campinas in the rainy season of 1977, 1978 and 1979. 'Carioca', 'Moruna' and 'Aroana' were used as controls for lines of Diversos, Preto and Chumbinho groups, respectively.

The results showed that the lines 5-9-4-3-1-4, 5-9-4-3-1-5, 18-1-6 and 5-9-4-3-1-6, with mean yields of $2,100,2,079,2,055$ and $2,028 \mathrm{~kg} / \mathrm{ha}$ were superior to the control 
Moruna, which yielded $1,580 \mathrm{~kg} / \mathrm{ha}$, at $5 \%$ level. None of Chumbinho lines outyielded Aroana although high mean yield was obtained by 5-1-1-5-1-9 with 2,336 $\mathrm{kg} / \mathrm{ha}$ compared with $2,136 \mathrm{~kg} / \mathrm{ha}$ got by the control. On the other hand, the lines 10-3-1 and 10-6-2 with means of 3,133 and $2,823 \mathrm{~kg} / \mathrm{ha}$ outyielded Carioca which obtained 2,375 and $2,355 \mathrm{~kg} / \mathrm{ha}$, respectively. The effect of year was significant in 11 out of the 12 groups of experiments while the interaction treatment $\mathrm{x}$ year was observed in two of them.

The best lines will be included in the regional trials and seeds of some of them increased in large quantities for releasing to the growers of Campinas region.

\section{REFERENCIAS BIBLIOGRAFICAS}

1. INSTITUTO BRASILEIRO DE GEOGRAFIA E ESTATISTICA. Anuário Estatístico do Brasil. Rio de Janeiro, IBGE, 1978. v.39. p. 367.

2. POMPEU, A. S. Linhagens de feijoeiro (Phaseolus vulgaris) resistentes ao fungo da antracnose (Colletotrichum lindemuthianum). Summa Phytopathologica, Piracicaba, 5:148-152, 1979.

3. — \& PARADELA FILHO, O. Novas linhagens de feijoeiro (Phaseolus vulgaris) dos grupos Rosinha e Roxinho, resistentes ao fungo da antracnose (Colletotrichum lindemuthianum). Summa Phytopathologica, Piracicaba, 5:153-158, 1979.

4. ZAUMEYER, W. J. \& THOMAS, H. R. A monografic study of bean diseases and methods for their control. Washington, U. S. Department of Agriculture, 1957. 255p. (Technical Bulletin, 868) 